\title{
Xanthone derivatives could be potential antibiotics: virtual screening for the inhibitors of enzyme I of bacterial phosphoenolpyruvate-dependent phosphotransferase system
}

\author{
Kuo-Jien Huang ${ }^{1}$, Shih-Hung Lin ${ }^{1}$, Meei-Ru Lin ${ }^{2}$, Hao Ku ${ }^{3}$, Natalia Szkaradek ${ }^{4}$, Henryk Marona ${ }^{4}$, Alvin $\mathrm{Hsu}^{5}$ \\ and David Shiuan ${ }^{1}$
}

The phosphoenolpyruvate phosphotransferase system (PTS) is ubiquitous in eubacteria and absent from eukaryotes. The system consists of two phosphoryl carriers, enzyme I (EI) and the histidine-containing phosphoryl carrier protein (HPr), and several PTS transporters, catalyzing the concomitant uptake and phosphorylation of several carbohydrates. Since a deficiency of El in bacterial mutants lead to severe growth defects, El could be a drug target to develop antimicrobial agents. We used the 3D structure PDB 1ZYM of Escherichia coli El as the target to virtually screen the potential tight binders from NPPEDIA (Natural Product Encyclopedia), ZINC and Super Natural databases. These databases were screened using the docking tools of Discovery Studio 2.0 and the Integrated Drug Design System IDDS. Among the many interesting hits, xanthone derivatives with reasonably high Dock scores received more attentions. Two of the xanthone derivatives were obtained to examine their capabilities to inhibit cell growth of both Gram-positive and Gram-negative bacterial strains. The results indicate that they may exert the inhibition effects by blocking the El activities. We have demonstrated for the first time that the xanthone derivatives have high potential to be developed as future antibiotics.

The Journal of Antibiotics (2013) 66, 453-458; doi:10.1038/ja.2013.30; published online 1 May 2013

Keywords: antibiotics; enzyme I; PTS; virtual screening; xanthone derivatives

\section{INTRODUCTION}

The increasing resistance of bacterial pathogens to antibiotics has become a serious problem in global health care. The modification and improvement of currently used antibiotics has not kept up with the changing needs. Thus, the development of novel antimicrobial agents is of great interest to both academia and the pharmaceutical industry. Other than the cell-wall-related molecular targets, the bacterial phosphoenolpyruvate (PEP)-dependent phosphotransferase system (PTS) is ubiquitously distributed in eubacteria and absent from eukaryotes. The PTS system catalyzes the concomitant uptake and phosphorylation of carbohydrates. ${ }^{1}$ The PTS generally consists of phosphoryl carrier PEP-dependent His-protein kinase, namely enzyme I (EI), histidine containing phosphoryl carrier protein (HPr) and several PTS transporters (sugar-specific EIIA, EIIB and membrane-bound EIIC subunits). In Escherichia coli, the PTS phosphorylates hexoses, hexitols and several disaccharides but not other sugars; such as, lactose, ribose and other pentoses. The system is also involved in chemotaxis, catabolite repression, signal transduction and allosteric regulation of metabolic enzymes and transporters in response to the availability of carbohydrates. ${ }^{2,3}$

The sequential transfer of the phosphoryl group from PEP to the transported carbohydrates keeps the sugars inside the cell, and is critical for bacterial growth. Therefore, blocking the phosphoryl transfer could prove to be a highly effective strategy for developing new antibiotics. The first step in sugar uptake by the PTS is the transfer of the phosphoryl group from PEP to EI, an indispensable component of the overall system. Because EI is a conserved and unique protein in prokaryotes and bear no similarity to eukaryotic proteins, it could provide an excellent target for developing antimicrobial agents. ${ }^{4}$ The E. coli EI monomer contains 575 amino acids $(63.5 \mathrm{kDa})$, undergoes a monomer/dimer transition and only the dimer form accepts the phosphoryl group from PEP. The crystal structure of EI reveals a dimeric protein in which each subunit comprises three domains: a domain that binds the partner HPr;

${ }^{1}$ Department of Life Science and Institute of Biotechnology, Interdisciplinary Program of Bioinformatics, National Dong Hwa University, Hualien, Taiwan; ${ }^{2}$ nnstitute of Biotechnology, National Cheng Kung University, Tainan, Taiwan; ${ }^{3}$ Department of Biological Sciences and Technology, I-Shou University, Kaohsiung, Taiwan; ${ }^{4}$ Department of Bioorganic Chemistry, Jagiellonian University Medical College, Krakow, Poland and ${ }^{5}$ Breadth Technology, Taipei, Taiwan

Correspondence: Professor D Shiuan, Department of Life Science and Institute of Biotechnology, Interdisciplinary Program of Bioinformatics, National Dong Hwa University, Hualien 974, Taiwan.

E-mail: shiuan@mail.ndhu.edu.tw

Received 5 April 2012; revised 14 March 2013; accepted 21 March 2013; published online 1 May 2013 
a domain that carries the phosphorylated histidine residue (His-189); and a PEP-binding domain. ${ }^{5}$ The PEP-binding site is occupied by $\mathrm{Mg}$ $(2+)$ and oxalate, and the phosphorylated His-189 is in line for phosphotransfer to and from the ligand. Thus, the structure represents an enzyme intermediate just after phosphotransfer from PEP and before a conformational transition that brings His-189 into proximity with the phosphoryl group acceptor, His-15 of HPr. ${ }^{5,6}$

Although a functional PTS is not necessary for the growth of E. coli on a complex medium, pts mutants of enteric bacteria cannot grow on defined media containing non-PTS sugars; such as, lactose as the only carbon source. ${ }^{1}$ In a murine model, the PTSI mutants of S. typhimurium were shown to have an attenuated virulence, with the LD50 (lethal dose 50\%) being two and three logs above the wild-type strain. ${ }^{7}$ The PTSI inhibitors may cause depletion of PEP, repression of catabolite-controlled genes and inhibition of carbohydrate transport, thus compromising cell growth and infectivity. ${ }^{4}$ Given that a deficiency of EI in bacterial mutants leads to severe growth defects in the bacteria, ${ }^{8}$ we therefore aimed to investigate novel inhibitors of EI as a potential new family of antibiotics.

\section{RESULTS AND DISCUSSION}

Virtual screening for EI inhibitors

The 3D structure PDB $1 \mathrm{ZYM}^{5}$ of the EI of the PTS of E. coli was downloaded from the Protein Data Bank (http://www.rcsb.org./) and

a
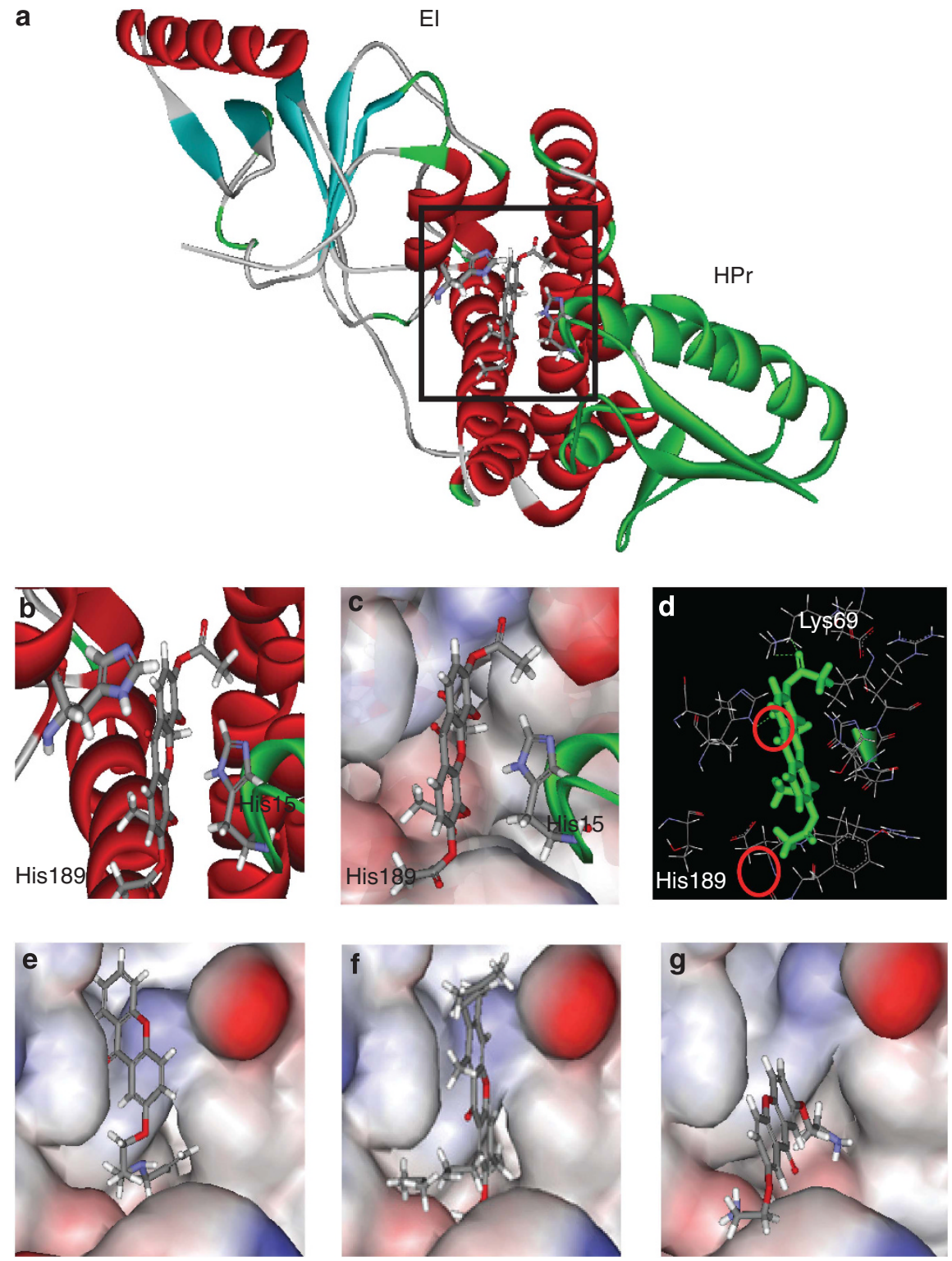

Figure 1 Molecular docking. (a) Model structure displays the molecular docking of the ligand molecule (xanthone derivative, ZINC14764604; 4, 5, 6-triacetyloxy-9-oxoxanthen-3-yl) acetate) with the EI-HPr (histidine-containing phosphoryl carrier protein) complex, PDB 3EZA. The enzyme I (EI) structure contains two parallel helix (red) and a short helix (red, upper left) interconnected by a loop and $\beta$-sheet structure. The protein Hpr (green, lower right) interacts with the parallel helix region of El. (b) A close-up view of the ligand-protein interaction. The ligand molecule lay in between the His189 of El and His 15 of HPr (the extruded side chains of His189 and His15 are shown in rod shape). (c) Surface display of the interaction of the ligand molecule with His189 of El and His15 of HPr. (d) Model structure of the ligand-protein interaction. The dashed green lines indicate that the ligand molecule (green) may form hydrogen bonds with Lys69 and His189 of the El protein. (e) Orientation of compound no. 9 in the binding pocket of El. (f) Orientation of $\alpha$-mangostin in the binding pocket of El. (g) Orientation of ZINCO4392753 in the binding pocket of El. 
fixed with the forcefield CHARMn of DS 2.0 to add up the hydrogen atoms, partial charges and missing residues. The potential binding sites on PDB 1ZYM were predicted and trimmed for docking. Then, the small-molecule database NPPEDIA was screened with the Receptor-Ligand Interactions protocols of DS 2.0 to identify ligand molecules that may bind tightly with 1ZYM and have high Dock scores. Among the many hits, one compound with a relatively high docking score (Dock score 55) gained our attention mainly because of its origin. The compound was 4, 5, 6-triacetyloxy-9-oxoxanthen-3-yl) acetate and was found to be a xanthone derivative, and it also appears in the ZINC database as ZINC14764604. Many xanthone derivatives are found in rich supply in Garcinia mangostana, the popular tropical fruit mangosteen, and in Tripterospernum taiwanense, a plant endemic to high mountain regions in Taiwan. ${ }^{9}$ As shown in Figure 1, the compound lies down in the cleft of the parallel helix of EI and may block the phosphotransfer path between the residue His189 of EI and residue His 15 of HPr protein. ${ }^{5}$ Further analysis of the ligand-protein interaction reveals that the ligand molecule may form two hydrogen bonds with Asp 189 and one hydrogen bond with Lys69 of EI protein, as shown in Figure 1d.

\section{Analysis of selected xanthone derivatives}

The chemical structure of xanthone forms the central core of many naturally occurring organic compounds. Several naturally occurring xanthone derivatives have been reported; such as, $\alpha$-mangostin, ${ }^{10}$ $\beta$-mangosten, ${ }^{11} \gamma$-mangosten, ${ }^{12} 8$-deoxygartanin ${ }^{13}$ and garcinone E. ${ }^{14}$ In a recent study, several different 2-xanthone derivatives were synthesized and some of them appeared to display antifungal and antibacterial properties. ${ }^{9}$ Two of the synthesized 2-xanthone derivatives; namely, compound nos. 9 and 11, which were shown to display antibacterial effects, were chosen for docking analysis in this study. In addition, several xanthone derivatives were identified from the ZINC database. They include ZINC04392753, ZINC03926314, ZINC08789174, ZINC04083849, ZINC08489503, ZINC04083211, ZINC04083847 and ZINC04083599. Thus, a total of 15 xanthone derivatives were selected in the current virtual study for analysis of their potential binding capabilities with EI protein. The International Union of Pure and Applied Chemistry (IUPAC) names and molecular structures of the selected xanthone derivatives are tabulated in Table 1 and Figure 2, respectively. Their interactions with EI protein were further analyzed through DS modeling. The docking scores, molecular weights, the predicted physical properties; such as, xLogP, HBD (number of hydrogen-bond donors), HBA (number of hydrogen-bond acceptors) and the number of predicted hydrogen bonds were tabulated.

As shown in Table 2, most of the compounds exhibited Dock scores in the range of 50-60, but compound ZINC04392753 and ZINC03926314 attained substantially higher scores of 173 and 78.4, respectively. The newly synthesized compounds; such as, compound nos. 9 and 11 attained relatively lower Dock and PMF scores. Two of the compounds, garcinone E and ZINC08789174, attained average Dock scores but exhibited extremely high PMF scores. These discrepancies between the docking scores are really difficult to explain. Our initially identified xanthone derivative (ZINC14764604) and three compounds with relatively low (compound no. 9), average ( $\beta$-mangostin) and high (ZINC04392753) Dock scores were chosen for comparison of their virtual binding capabilities. Figures $1 \mathrm{c}$ and e-g display the four model structures of the ligand-protein interactions. We observed that all four ligand molecules dwell in the same position of the binding cavity of EI protein, but ligand ZINC04392753 protrudes a little further into the center of the cavity. Comparing the HBD, HBA and the predicted numbers of hydrogen bonds between the ligands and EI, we noted that the ligand ZINC04392753 attained the highest values, and compound nos. 9 and 11 possessed lower values. Thus, the capability to form stable hydrogen bonds may explain the differences among the selected compounds, which otherwise interacted with EI in a geometrically similar manner. To examine the potential toxicities of the selected xanthone derivatives, we also analyzed these compounds through preADMET and DSSTox analysis. The predictions revealed that 8-deoxygartanin, STOCKIN-31952 and ZINC08789174 may display cellular toxicities (as shown in Table 2).

\section{Evaluation of inhibitory effects of the selected compounds on bacterial growth}

As the phosphorylated form of EI is capable of transferring its phosphoryl group to acetate kinase, and communicate with Krebs cycle and the EI-HPr pair can influence chemotaxis via CheA or CheY chemostatic proteins, ${ }^{15}$ a direct evaluation of EI inhibitions seems to be not very feasible. Therefore, the experimental evaluation of inhibitory capabilities of the selected compounds on bacterial

Table 1 The IUPAC names of the 15 selected xanthone derivatives

\begin{tabular}{|c|c|}
\hline Name & IUPAC \\
\hline Derivative ZINC14764604 & (4,5,6-Triacetyloxy-9-oxoxanthen-3-yl) acetate \\
\hline Garcinone E & 2-[3-(Prop-2-enylamino) propoxy] xanthen-9-one \\
\hline 8-Deoxygartanin & 1,3,5-Trihydroxy-2,4-bis(3-methylbut-2-enyl) xanthen-9-one \\
\hline$\gamma$-Mangostin & 1,3,6,7-Tetrahydroxy-2,8-bis(3-methylbut-2-enyl) xanthen-9-one \\
\hline$\alpha$-Mangostin & 1,3,6-Trihydroxy-7-methoxy-2,8-bis(3-methylbut-2-enyl) xanthen-9-one \\
\hline$\beta$-Mangostin & 1,6-Dihydroxy-3,7-dimethoxy-2,8-bis(3-methylbut-2-enyl) xanthen-9-one \\
\hline STOCKIN-31952 & 2,8-Dihydroxy-1,6-dimethoxyxanthen-9-one \\
\hline Compound no. 9 & 2-[3-(Prop-2-enylamino) propoxy] xanthen-9-one \\
\hline Compound no. 11 & 6-Chloro-2-(methylaminomethyl) xanthen-9-one \\
\hline ZINC04392753 & 2,7-Bis(2-aminoethoxy) xanthen-9-one \\
\hline ZINC03926314 & 5,7-Diacetyl-6-(5-carboxy-6,7-dihydroxy-4-oxochromen-3-yl)-2,3-dihydroxy-9-oxoxanthene-1-carboxylic acid \\
\hline ZINC08789174 & Propan-2-yl2-(\{9-oxo-3-[2-oxo-2-(propan-2-yloxy)ethoxy]-9H-xanthen-1-yl\}oxy)acetate \\
\hline ZINC04083211 & 1,3-Bis(2-oxopropoxy)-9H-xanthen-9-one \\
\hline ZINC04083847 & Methyl 2-(\{3-[(1-methoxy-1-oxopropan-2-yl)oxy]-9-oxo-9H-xanthen-1-yl\}oxy) propanoate \\
\hline ZINC04083599 & Methyl 4-\{[(1-hydroxy-9-oxo-9H-xanthen-3-yl)oxy]methyl\}benzoate \\
\hline
\end{tabular}

Abbreviations: IUPAC, International Union of Pure and Applied Chemistry. 
<smiles>CC(=O)Oc1ccc2c(=O)c3ccc(OC(C)=O)c(OC(C)=O)c3oc2c1OC(C)=O</smiles>

Derivative-ZINC14764604<smiles>CC(C)=CCc1c(O)cc2oc3cc(O)c(O)c(CC=C(C)C)c3c(=O)c2c1O</smiles>

$\gamma$-mangostin<smiles>COC1=CC(O)=C2C(=O)c3c(ccc(c3OC)O1)Oc1ccc(O)cc12</smiles>

STOCKIN-31952

ZINC04392753<smiles>CC(=O)COc1cc(OCC(C)=O)c2c(=O)c3ccccc3oc2c1</smiles>

ZINC04083211<smiles>CC(C)=CCc1cc2c(=O)c3c(CC=C(C)C)c(O)c(O)c(CC=C(C)C)c3oc2cc1O</smiles>

Garcinone E<smiles>COc1c(O)cc2oc3cc(O)c(CC=C(C)C)c(O)c3c(=O)c2c1CC=C(C)C</smiles>

$\alpha$-mangostin<smiles>C=CCNCCCOC1CCc2oc3ccccc3c(=O)c2C1</smiles>

Compound \#9<smiles>CC(=O)c1cc2c(=O)c3c(C(=O)O)c(O)c(O)cc3oc2c(C(C)=O)c1-c1coc2cc(O)c(O)c(C(=O)O)c2c1=O</smiles>

ZINC03926314<smiles>COC(=O)C(C)Oc1cc(OC(C)C(=O)OC)c2c(=O)c3ccccc3oc2c1</smiles>

ZINC04083847<smiles>CC(C)=CCc1c(O)c(CC=C(C)C)c2oc3c(O)cccc3c(=O)c2c1O</smiles>

8-deoxygartanin ${ }^{\star}$<smiles>COc1cc2oc3cc(O)c(OC)c(CC=C(C)C)c3c(=O)c2c(O)c1CC=C(C)C</smiles>

$\beta$-mangostin<smiles>CNCc1ccc2oc3cc(Cl)ccc3c(=O)c2c1</smiles>

Compound \#11<smiles>CC(C)OC(=O)COc1cc(OCC(=O)OC(C)C)c2c(=O)c3ccccc3oc2c1</smiles>

ZINC08789174<smiles>COC(=O)c1ccc(COc2cc(O)c3c(=O)c4ccccc4oc3c2)cc1</smiles>

ZINC04083599

Figure 2 The molecular structures of the 15 selected xanthone derivatives. A full color version of this figure is available at The Journal of Antibiotics journal online.

growth was performed. We have chosen E. coli $\mathrm{DH} 5 \alpha$, . aeruginosa PU-21, which both are Gram-negative bacteria, and S. aureus, a facultative anaerobic Gram-positive coccal bacterium, as the representatives of the growth inhibition assays. Among the many xanthone derivatives we have identified as potential EI inhibitors, only compound nos. 9 and 11 are available for the assays. ${ }^{9}$ As shown in
Figures $3 \mathrm{a}$ and $\mathrm{b}$, both compound nos. 9 and 11 exhibit very similar inhibitory pattern on $E$. coli cell growth, with $\mathrm{IC}_{50}$ of approximately 300 and $200 \mu \mathrm{M}$, respectively. More than three trials have been carried out for $P$. aeruginosa PU-21 experiments. However, as shown in Figures $3 c$ and $d$, we still failed to get very accurate dose-dependence curves after more than three trials. The $\mathrm{IC}_{50}$ of compound nos. 9 and 
Table 2 The docking scores and physical properties of the 15 selected ligand molecules

\begin{tabular}{|c|c|c|c|c|c|c|c|}
\hline Name & $\begin{array}{l}\text { Dock } \\
\text { score }\end{array}$ & $\begin{array}{l}\text { PMF } \\
\text { score }\end{array}$ & $M W$ & $x \log P$ & $H B D$ & $H B A$ & $\begin{array}{c}H \\
\text { bond }\end{array}$ \\
\hline $\begin{array}{l}\text { Derivative } \\
\text { ZINC14764604 }\end{array}$ & 55.0 & -89.0 & 428.3 & 2.0 & 0 & 10 & 3 \\
\hline Garcinone $\mathrm{E}$ & 57.1 & -140.0 & 448.5 & 4.1 & 3 & 6 & 1 \\
\hline 8-Deoxygartanin ${ }^{a}$ & 50.2 & -132.0 & 380.4 & 6.3 & 3 & 5 & 1 \\
\hline$\gamma$-Mangostin & 60.1 & -122.0 & 396.4 & 5.9 & 4 & 6 & 2 \\
\hline$\alpha$-Mangostin & 50.3 & -103.0 & 410.4 & 6.3 & 6 & 3 & 1 \\
\hline$\beta$-Mangostin & 50.1 & -89.0 & 434.4 & 6.6 & 2 & 6 & 1 \\
\hline STOCKIN-31952a & 54.1 & -103.0 & 288.2 & 2.7 & 2 & 6 & 1 \\
\hline Compound no. 9 & 44.0 & -106.0 & 309.3 & 4.1 & 1 & 4 & 0 \\
\hline Compound no. 11 & 34.0 & -58.0 & 273.7 & 3.0 & 1 & 3 & 0 \\
\hline ZINC04392753 & 173.0 & -54.3 & 316.3 & 1.7 & 2 & 6 & 4 \\
\hline ZINC03926314 & 78.4 & -118.4 & 574.4 & 2.3 & 6 & 14 & 3 \\
\hline ZINC08789174a & 60.7 & -140.0 & 428.4 & 4.3 & 0 & 8 & 2 \\
\hline ZINC04083211 & 58.4 & -92.6 & 340.3 & 1.8 & 0 & 6 & 2 \\
\hline ZINC04083847 & 56.8 & -85.2 & 400.3 & 2.9 & 0 & 8 & 2 \\
\hline ZINC04083599 & 52.5 & -111.0 & 376.3 & 4.5 & 1 & 6 & 1 \\
\hline
\end{tabular}

Abbreviations: $\mathrm{H}$, hydrogen; $\mathrm{HBA}$, number of hydrogen-bond acceptors; $\mathrm{HBD}$, number of hydrogen-bond donors; PMF, potential of mean force; MW, molecular weight.

aThe compounds may display cellular toxicities based on the preADMET and DSSTox predictions.
11 toward $P$. aeruginosa PU-21 were estimated to be approximately 200 and $300 \mu \mathrm{M}$, respectively. We have also noted that the growth rate of $S$. aureus is much higher than E. coli, as shown in Figures $3 \mathrm{e}$ and $\mathrm{f}$. The IC $_{50}$ of both compound nos. 9 and 11 can be estimated to be approximately $250 \mu$ m. These inhibitory effects in $P$. aeruginosa had not been observed before. ${ }^{9}$ We speculate that the previous inhibition zone assays ${ }^{9}$ did not reveal these inhibition effects on $P$. aeruginosa, probably due to its rather low growth rate. As the Dock and PMF scores of compound nos. 9 and 11 are rather low in our docking studies as shown in Table 2, it is reasonable to anticipate that many other xanthone derivatives with higher Dock scores may exhibit much higher bacterial growth inhibition effects.

\section{Xanthone derivatives may be developed as future antibiotics}

The discovery of sulfonamides and $\beta$-lactam antibiotics in the 1930s had a profound effect on human health. Since then, various antibiotic drug classes have been investigated. However, many recent trends in antibiotics; such as, those drugs that have been developed since 2000, still have been based on previously identified scaffolds, with only a few exceptions. ${ }^{16}$ Obviously, novel templates for more modern antibiotics; such as, the inhibitors of elongation-condensing enzyme FabF of bacterial type II fatty acid biosynthesis, ${ }^{17}$ are needed in antibiotics industry. Through rational drug design, this study has demonstrated the feasibility of discovering potential EI inhibitors
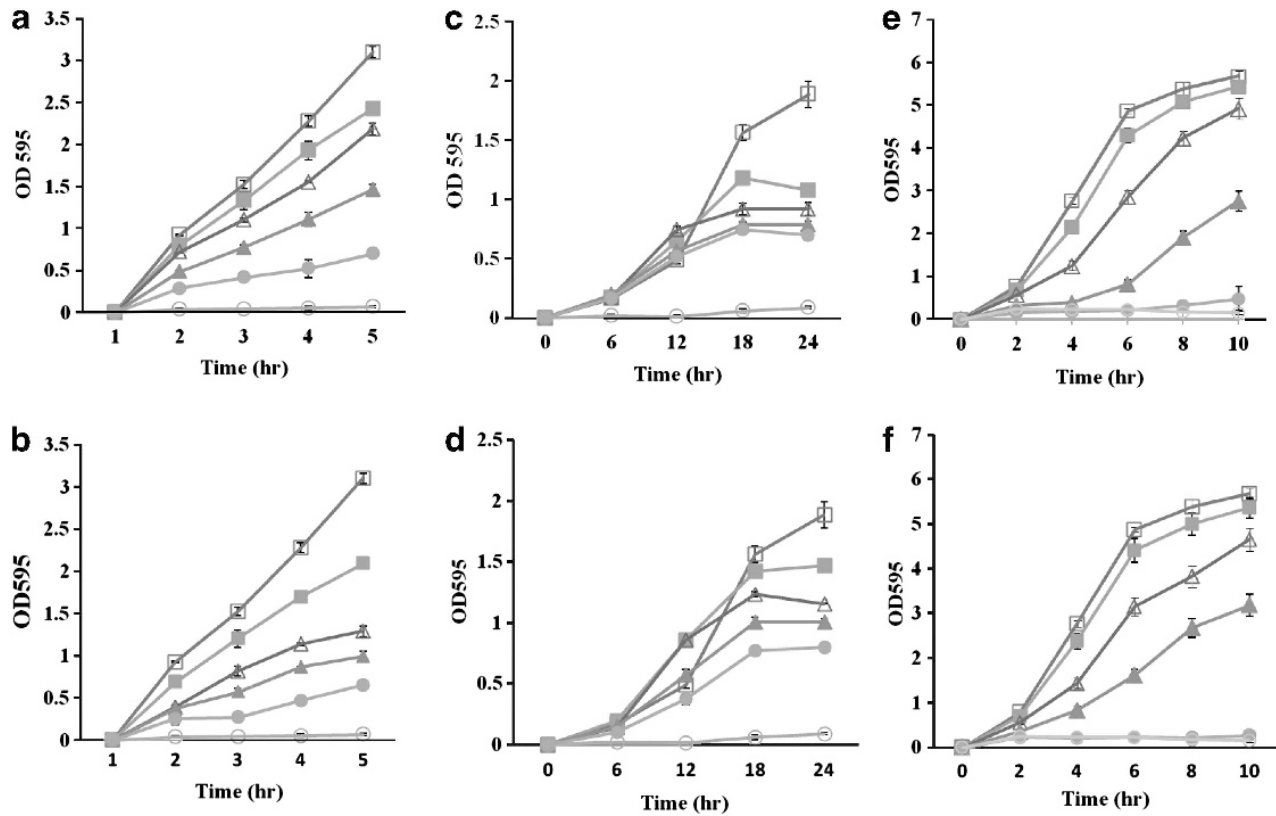

Figure 3 Bacterial growth inhibition assays. (a) Inhibition of Escherichia coli growth in LB (Luris-Bertani) medium with nalidixic acid (20 $\mu$ g ml ${ }^{-1}$ ) by the presence of compound no. 9, The notions $\square, \boldsymbol{\square}, \Delta, \boldsymbol{\Delta}, \boldsymbol{\bullet}$ and $\bigcirc$ represent the negative control $(0 \mu \mathrm{M}$ of compound no. 9), $100 \mu \mathrm{m}, 200 \mu \mathrm{m}, 300 \mu \mathrm{m}$, $400 \mu \mathrm{m}$ and the positive control (tetracycline $15 \mu \mathrm{g} \mathrm{ml}-1$ ), respectively. Each sample has the same amount of dimethylsulfoxide (DMSO) (0.5\%). (b) Inhibition of Escherichia coli growth in LB medium with nalidixic acid $\left(20 \mu \mathrm{g} \mathrm{ml}^{-1}\right)$ by the presence of compound no. 11 . The notions $\square, \boldsymbol{\square}, \Delta, \boldsymbol{\Lambda}, \bullet$ and $\bigcirc$ represent the negative control $(0 \mu \mathrm{M}$ of compound no. 11), $100 \mu \mathrm{m}, 200 \mu \mathrm{m}, 300 \mu \mathrm{m}, 400 \mu \mathrm{m}$ and the positive control (tetracycline $15 \mu \mathrm{gml}-1$ ), respectively. Each sample has the same amount of DMSO. (c) Inhibition of $P$. aeruginosa growth in TSB buffer with ampicillin $\left(50 \mu \mathrm{g} \mathrm{ml}{ }^{-1}\right)$, by the presence of compound no. 9, The notions $\square, \mathbf{\square}, \Delta, \boldsymbol{\Delta}, \bullet$ and $\bigcirc$ represent the negative control ( $0 \mu \mathrm{m}$ of compound no. 9), $100 \mu \mathrm{m}, 200 \mu \mathrm{m}, 250 \mu \mathrm{m}, 300 \mu \mathrm{m}$ and the positive control (kanamycin $50 \mu \mathrm{g} \mathrm{ml}-1$ ), respectively. Each sample has the same amount of DMSO. (d) Inhibition of $P$. aeruginosa growth in TSB buffer with ampicillin $\left(50 \mu \mathrm{g} \mathrm{ml}^{-1}\right)$, by the presence of compound no. 11. The notions $\square, \mathbf{\square}, \Delta, \boldsymbol{\Delta}, \boldsymbol{\bullet}$ and $\bigcirc$ represent the negative control $(0 \mu \mathrm{m}$ of compound no. 11), $100 \mu \mathrm{m}, 200 \mu \mathrm{m}, 250 \mu \mathrm{m}, 300 \mu \mathrm{m}$ and the positive control (kanamycin $50 \mu \mathrm{g} \mathrm{ml}{ }^{-1}$ ). Each sample has the same amount of DMSO. (e) Inhibition of S. aureus growth in LB medium with chloramphenicol $\left(30 \mu \mathrm{g} \mathrm{ml} \mathrm{l}^{-1}\right)$, by the presence of compound no. 9. The notions $\square, \boldsymbol{\square}, \Delta, \boldsymbol{\Delta}, \boldsymbol{\bullet}$ and $\bigcirc$ represent the negative control ( $0 \mu \mathrm{m}$ of compound no. 9), $100 \mu \mathrm{m}, 200 \mu \mathrm{m}, 300 \mu \mathrm{m}, 400 \mu \mathrm{m}$ and the positive control (tetracycline $15 \mu \mathrm{g} \mathrm{ml} \mathrm{m}^{-1}$ ), respectively. (f) Inhibition of $S$. aureus growth LB medium with chloramphenicol $(30 \mu \mathrm{g} \mathrm{ml}-1)$, by the presence of compound no. 11. The notions $\square, \boldsymbol{\square}, \Delta, \mathbf{\Lambda},-\mathbf{a}$ and $\bigcirc$ represent the negative control $\left(0 \mu \mathrm{M}\right.$ of compound no. 11), $100 \mu \mathrm{m}, 200 \mu \mathrm{M}, 300 \mu \mathrm{m}, 400 \mu \mathrm{m}$ and the positive control (tetracycline $\left.15 \mu \mathrm{g} \mathrm{ml}{ }^{-1}\right)$, respectively. Each sample has the same amount of DMSO (0.5\%). A full color version of this figure is available at The Journal of Antibiotics journal online. 
through virtually screening the natural product databases. Furthermore, we have demonstrated that the xanthone-related compound nos. 9 and 11 indeed possess antibacterial properties. As the PTS system is ubiquitous in bacteria and absent in human, inhibitors; such as, xanthone derivatives of the PTS pathway, could be novel templates to develop next generation of effective antibiotics.

\section{MATERIALS AND METHODS}

\section{Protein structure for docking}

The 3D structure PDB $1 \mathrm{ZYM}^{5}$ and $2 \mathrm{HWG}^{6}$ of the EI of the PTS of E. coli were chosen as the molecular targets and downloaded from the Protein Data Bank (http://www.rcsb.org/pdb). The structures were fixed with the forcefield CHARMn (Chemistry at Harvard Macromolecular mechanics) to add up the hydrogen atoms, partial charges and missing residues. ${ }^{18}$

\section{Small-molecule database}

This study initially used NPPEDIA (Natural Product Encyclopedia, assembled by Breadth Technologies, Taipei, Taiwan), which is a recently compiled commercial database containing more than 70000 verified compounds from approximately 10000 plants. The Zinc Database (http://zinc.docking.org/) 19 and Super Natural Database (http://bioinformatics.charite.de/supernatural/) were also used for docking.

\section{Docking and scoring function}

After downloading PDB $1 \mathrm{ZYM}^{5}$ of the EI of PTS of E. coli, its potential binding sites were predicted by the binding site tools of DS 2.0 (based on the largest cavities on the receptor surface). The largest binding site was further trimmed to delete minor web-like regions, before docking with the ReceptorLigand Interactions protocols of DS 2.0. The small-molecule databases were docked using the LigandFit software (in DS 2.0), which provides a shape-based method for accurately docking ligands into protein active sites. ${ }^{20}$ The method employs a cavity detection algorithm and a shape comparison filter is combined with a Monte Carlo conformational search for generating ligand poses consistent with the active site shape. The docked poses were then analyzed using the scoring functions, including Dock scores, LigScorel and LigScore2, PLP1 and PLP2, Jain, potential of mean force (PMF) and Ludi scores. In this study, the Dock scores ${ }^{20}$ was used as the primary scoring function to rank the receptor-ligand internal energies. Among the other functions, Jain's primary terms involve hydrophobic and polar complementarity, with additional terms for entropic and solvation effects. ${ }^{21}$ The PMF is a knowledge-based approach that exploits structural information of known protein-ligand complexes and calculates pairwise interactions of all interatomic pairs of a receptor-ligand system. ${ }^{22}$ The Ludi method investigates parameters; such as, the number and geometry of hydrogen bonds and ionic interactions between the protein and the ligand, the size of the lipophilic contact surface, the flexibility of the ligand, the electrostatic potential in the binding site, water molecules in the binding site, cavities along the proteinligand interface and specific interactions between aromatic rings. ${ }^{23}$

\section{ADMET prediction}

The absorption, distribution, metabolism, excretion, toxicity (ADMET) properties of the virtually selected compounds were further estimated using the web server preADMET (http://preadmet.bmdrc.org/) and DSSTox (http://www. epa.gov/ncct/dsstox/). In fact, we knew that these programs are based on certain prediction models and their prediction results are only served as reference.

\section{Bacterial growth inhibition assay}

To evaluate the inhibitory effects of selected compounds, the following bacterial strains were used: E. coli DH5 $\alpha$ (fhuA2 $\Delta$ (argF-lacZ)U169 phoA glnV44 Ф80 $\Delta$ (lacZ)M15 gyrA96 recA1 relA1 endA1 thi-1 hsdR17); Pseudomonas aeruginosa PU-21 ${ }^{24}$ and Staphylococcus aureus BCRC-17569 from BCRC (Bio-resource Collection and Research Center, Hsinchu, Taiwan). In the assays, E. coli DH5 $\alpha$ was grown in LB (Luris-Bertani) medium with nalidixic acid $\left(2 \mu \mathrm{g} \mathrm{ml}^{-1}\right)$, S. aureus was grown in TSB buffer (per liter contains: trypton $17 \mathrm{~g}$, soytone $3 \mathrm{~g}, \mathrm{NaCl} 5 \mathrm{~g}, \mathrm{KH}_{2} \mathrm{PO}_{4} 2.5 \mathrm{~g}$ and glucose $2.5 \mathrm{~g})$ with ampicillin $\left(50 \mu \mathrm{g} \mathrm{ml}^{-1}\right)$ and $P$. aeruginosa was grown in LB medium with chloramphenicol $\left(30 \mu \mathrm{g} \mathrm{ml}^{-1}\right)$. All of the bacterial mixtures were supplemented with equal amount of dimethylsulfoxide (DMSO) (0.5\%) for preparing the organic compounds. The bacteria (initial volume $3 \mathrm{ml}$ ) with various amounts of added compounds were cultured at $37^{\circ} \mathrm{C}$ and shaked at 140 r.p.m. At different time-points, $0.5 \mathrm{ml}$ was sampled for assaying the bacterial growth by measuring $\mathrm{OD}_{595}$. Three or more independent experiments were performed and the standard deviations were estimated.

\section{ACKNOWLEDGEMENTS}

This work was partially supported by a grant (NSC97-2311-B259-04-MY3) from the National Science Council, ROC.

1 Postma, P. W., Lengeier, J. W. \& Jacobson, G. R. in Escherichia coli and Salmonella typhimurium: Cellular and Molecular Biology 1149-1174, (American Society for Microbiology Press, Washington DC, 1996).

2 Deutscher, J., Francke, C. \& Postma, P. W. How phosphotransferase system-related protein phosphorylation regulates carbohydrate metabolism in bacteria. Microbiol. Mol. Biol. Rev. 70, 939-1031 (2006).

3 Saier, M. H., Chauvaux, S., Deutscher, J., Reizer, J. \& Ye, J. J Protein phosphorylation and regulation of carbon metabolism in Gram-negative versus Gram-positive bacteria. Trends Biochem. Sci. 20, 267-271 (1995).

4 Mukhija, S. \& Erni, B. Phage display selection of peptides against enzyme I of the phosphoenolpyruvate:sugar phosphotransferase system (PTS). Mol. Microbio1. 25, 1159-1166 (1997).

5 Liao, D. I. et al. The first step in sugar transport: crystal structure of the amino terminal domain of enzyme I of the $E$. coli PEP: sugar phosphotransferase system and a model of the phosphotransfer complex with HPr. Structure 4, 861-872 (1996).

6 Teplyakov, A. et al. Structure of phosphorylated enzyme I, the phosphoenolpyruvate: sugar phosphotransferase system sugar translocation signal protein. Proc. Natl Acad. Sci. USA 103, 16218-16223 (2006).

7 Kok, M., Bron, G., Erni, B. \& Mukhija, S Effect of enzyme I of the bacteria phosphoenolpyruvate:sugar phosphotransferase system (PTS) on virulence in a murine mode1. Microbiology 149, 2645-2652 (2003).

8 Weaver, C. A., Chen, Y. Y. \& Burne, R. A Inactivation of the ptsI gene encoding enzyme of the sugar phosphotransferase system of Streptococcus salivarius: effects on growth and urease expression. Microbiology 146, 1179-1185 (2000).

9 Marona, $\mathrm{H}$. et al. Antifungal and antibacterial activity of the newly synthesized 2-xanthone derivatives. Arch. Pharm. 342, 9-18 (2009).

10 Stout, G. H. \& Krahn, M. M The structure of mangostin. Chem. Commun. 211-212 (1968).

11 Mahabusarakam, W., Wiriyachtra, P. \& Taylor, W Chemical constituents of Garcinia mangostana. J. Nat. Prod. 50, 474-478 (1987).

12 Jefferson, A. Q. A., Scheimann, F. \& Sim, K. Y Isolation of $\gamma$-mangostin from Garcinia mangostana and preparation of the natural mangostins by selective demethylation. Aust. J. Chem. 23, 2539-2543 (1970).

13 Hung, Y. L., Chen, C. C., Chen, Y. J., Huang, R. L. \& Shieh, B. J Three xanthones and a benzophenone from Garcinia mangostana. J. Nat. Prod. 64 903-906 (2001).

14 Asai, F., linuma, M., Tanaka, T. \& Tosa, H Xanthone from pericarps of Garcinia mangostana. Phytochemistry 39, 943-944 (1995).

15 Ginsburg, A. \& Peterkofsky, A Enzyme I: the gateway to the bacterial phosphoenolpyruvate: sugar phosphotransferase system. Arch. Biochem. Biophys. 397, 273-278 (2002).

16 Butler, M. S. \& Cooper, M. A Antibiotics in the clinical pipeline in 2011. J. Antibiot. 64, 413-425 (2011).

17 Martens, E. \& Demain, A. Platensimycin and platencin: promising antibiotics for future application in human medicine. J. Antibiot. 64, 705-710 (2011).

18 Brooks, B. R. et al. CHARMM: A program for macromolecular energy, minimization, and dynamics calculations. J. Comp. Chem. 4, 187-217 (1983).

19 Irwin, J. J. \& Shoichet, B. K ZINC-a free database of commercially available compounds for virtual screening. J. Chem. Inf Model 45, 177-182 (2005).

20 Venkatachalam, C. M., Jiang, X., Oldfield, T. \& Waldman, M LigandFit: a novel method for the shape-directed rapid docking of ligands to protein active sites. J. Mol. Graph. Model 22, 289-307 (2003).

21 Jain, A. N Scoring noncovalent protein-ligand interactions: a continuous differentiable function tuned to compute binding affinities. J. Comput. Aided Mol. Des. 10, 427-440 (1996).

22 Muegge, I. \& Martin, Y. C A general and fast scoring function for protein-ligand interactions: a simplified potential approach. J. Med. Chem. 42, 791-804 (1999).

23 Bohm, H. J Prediction of binding constants of protein ligands: a fast method for the prioritization of hits obtained from de novo design or 3D database search programs. J. Comput. Aided Mol. Des. 12, 309-323 (1998).

24 Chang, J. S. \& Law, W. S Development of microbial mercury detoxification processes using mercury-hyperresistant strain of Pseudomonas aeruginosa PU21. Biotechnol. Bioeng. 57, 462-470 (1998). 